\title{
Editorial
}

\section{O inominável e a transitoriedade}

\section{The nameless and transience}

Sonia Leite*1

O rompimento da barragem na cidade de Brumadinho repetição macabra do ocorrido em Mariana, no ano de 2015 - deixou a todos estupefatos. Crime ou tragédia? Alguns interrogaram. $\mathrm{O}$ fato é que uma tragédia anunciada é mais do que uma tragédia e revela, antes de tudo, o descaso das autoridades que teriam como função a fiscalização e a prevenção de acidentes, nas atividades das grandes empresas de mineração. Nesse sentido, a lama que invadiu a cidade, e que arrastou inúmeras vidas para a morte, desnudou, mais uma vez, a lógica predominante do lucro que banaliza a realidade da finitude da vida, do respeito ao outro e à natureza, além de apontar para a total ausência de respeito das autoridades diante dos direitos e da justiça social, fundamentos da vida em comum.

Apesar de ter a clareza de que esse terrível desastre, por sua complexidade, envolve inúmeras questões, inclusive aquelas que apontam para a necessária punição de seus responsáveis, minha proposta, aqui, é fazer uma breve reflexão,

*1 Centro Psiquiátrico RJ/Universidade do Estado do Rio de Janeiro - UERJ (Rio de Janeiro, RJ, Brasil). 
pela via da psicanálise, sobre o inominável, o traumático, na vida humana. Experiência radicalmente revelada pelos depoimentos dos sobreviventes.

Meu interesse, aqui, é destacar que, paradoxalmente, são essas situações extremas que convocam os sujeitos em sua capacidade mais primária de criação, ou, ainda, de recriação, no campo da cultura e dos laços sociais.

Tais pontos nos colocam em contato direto com aquilo que Freud destaca como as principais fontes da infelicidade humana, descritas no seu texto "O mal-estar na civilização" (1930/1977d).

Considera, nesse atualíssimo artigo, que o que chamamos de felicidade, no sentido estrito, provém da satisfação repentina de necessidades retidas em alto grau, sendo por isso mesmo um fenômeno episódico. Já a infelicidade, afirma, é muito menos difícil de ser experimentada, pois o sofrimento nos ameaça a partir de três direções. São elas: $1^{\text {a)}) ~ o s ~ d e s a s t r e s ~ d a ~ n a t u r e z a ~ e ~ d o ~}$ mundo exterior que podem se abater sobre nós com sua força destruidora; $2^{\mathrm{a}}$ ) a fragilidade de nossos corpos e, ainda, $3^{a}$ ) as dificuldades nas relações entre os homens, ou seja, nas relações sociais que, segundo Freud, provocam os piores e mais duros sofrimentos para os seres humanos.

Freud considera que sob a pressão de todas essas possibilidades de sofrimento, os homens acabam por moderar suas reivindicações de felicidade dedicando-se, muitas vezes, apenas à tarefa de evitar o sofrimento, em vez de buscar o prazer e a felicidade.

O sofrimento nos reporta ao desamparo primário, marca situada nas origens do sujeito e que desnuda nossa dependência ao Outro. Estar des-amparado, sem amparo, sem apoio, reporta ao horror do encontro com a ausência de sentido que algumas situações-limite engendram. Encontro com o inominável, ou seja, com aquilo que não se pode designar por um nome e que, por isso mesmo, é também o inqualificável, o insuportável, o doloroso. O que não se nomeia, escapa da vida, pois indica muitas vezes o impossível de ser comunicado.

De qualquer forma o que a psicanálise revela é que o inominável traumático é parte da existência, insistindo e retornando, de um modo ou de outro ao longo da vida, convocando-nos para uma reflexão sobre a importância do trabalho psíquico e da atividade de criação como possibilidade de contorno do não representável na experiência humana compartilhada.

A devastação ocasionada pelos desastres naturais, assim como pela guerra, ou mesmo pelos momentos de violência social, nos confronta, antes de qualquer coisa, com a fragilidade das conquistas civilizatórias, com o fato da finitude e com a necessidade do luto. 
São esses os temas que Freud irá tratar em dois artigos escritos em março/abril e novembro, de 1915, após a deflagração da Primeira Grande Guerra Mundial. Tais textos são de uma atualidade impressionante, exatamente porque descrevem que os momentos de catástrofe social nos confrontam, simultaneamente, com as três principais fontes de infelicidade indicadas, que ao se associarem parecem colocar o sujeito diante da falência da palavra que desaparece ante o silêncio do inominável.

O primeiro artigo, denominado "Reflexões sobre os tempos de guerra e de morte" (1915b/1977b), composto de duas partes, chama a atenção para a desorientação produzida pelo tempo da guerra e pelas informações unilaterais que se produzem sem a suficiente distância que possibilitaria aos cidadãos vislumbrar uma saída no futuro. Considera que toda pessoa que participou direta ou indiretamente desse acontecimento absurdo, sente-se confundido em sua orientação de vida e inibido em sua produtividade. Ou seja, a destruição momentânea das referências sociais, ocasionadas por tais experiências, seja ela qual for, ressalta a necessidade de o sujeito reencontrar, pelo menos dentro de si, e junto aos outros, um rumo que permita resgatar um lugar no mundo. O que enfatiza é a necessidade da simbolização daquilo que se apresenta, num primeiro momento, como o sem sentido. Para tanto, Freud indica que duas difíceis tarefas precisam ser enfrentadas: a desilusão e a morte.

A desilusão em relação à perda dos ideais sociais e dos projetos de vida, provocada pela natureza real do evento traumático, produz, paradoxalmente, a experiência do despertar. $O$ traumático nos desperta porque na maior parte do tempo estamos iludidos, sonhando ou fantasiando. A psicanálise nos ensina, de fato, que aquilo que condiciona a vida humana é a realidade psíquica, ou seja, um determinado modo de representar a realidade que se processa desde as origens do sujeito. Isso significa considerar que, de certo modo, construímos a realidade de acordo com nossos desejos e ilusões, fabricando, enfim, um lugar no mundo, a partir de determinadas expectativas que prometem a satisfação. Podemos, assim, dizer que passamos a maior parte do tempo sonhando, apesar dos olhos abertos, e que a radicalidade de determinados acontecimentos surpreendem obrigando-nos a acordar e a reconhecer aquilo que evitamos com todos os recursos psíquicos: a ideia da morte.

A guerra, assim como qualquer grande desastre natural ou social, nos conduzem a rever nossa atitude diante da morte, que é a tendência de colocá-la, como se diz, "de lado", de eliminá-la da vida, silenciando-a.

Freud (1915b/1977b) exemplifica essa atitude predominante por um provérbio alemão que é utilizado sempre que alguém se recusa a uma 
evidência: "Creio nisso tão pouco quanto na morte" (p. 327). A verdade é que a morte própria, a princípio, ninguém pode conceber. Ou, como indica Freud: "no fundo ninguém crê em sua própria morte [...] (pois) no inconsciente cada um de nós está convencido de sua própria imortalidade" (p. 327). E também da imortalidade dos entes amados, pois aqueles que amamos não deixam de ser uma continuidade da nossa própria existência.

Por isso Jacques Lacan (1974-75) certa vez falou, para uma plateia atônita, que ninguém tinha a menor apreensão da morte, pois caso contrário ninguém estaria ouvindo-o tão tranquilamente. Mais adiante, reforça essa ideia promulgando que a morte, nenhuma pessoa sabe, de fato, o que é! Pode-se completar: da morte ninguém quer nada saber.

Frequentemente são os escritores, os poetas e as crianças que conseguem falar mais diretamente do assunto. Certa feita a escritora Clarice Lispector se retirou subitamente de uma festa afirmando que ia embora porque ninguém ali estava interessado em falar sobre a morte. Freud por sua vez, no referido texto (1915a/1977a), dá o exemplo da criança que fala sem censura "Querida mãezinha, quando você morrer eu farei isso ou aquilo..." (p. 328). Por outro lado, Caetano Veloso, certa vez, expressando o desejo de muitos e assombrando alguns, afirmou: eu, não vou morrer.

Quando somos obrigados a despertar e a encarar a ocorrência de mortes ficamos profundamente atingidos e somos abalados em nosso narcisismo, nossas convicções e referências. Especialmente quando o fato é inesperado, ou seja, quando não nos permite um mínimo de preparação subjetiva.

Nossa tendência mais comum é desmentir a morte. Isso, por exemplo, aparece frequentemente nas palavras de um rapaz em análise: "Imagina se eu morro o que acontece com a minha vida, com meus filhos?". Ou ainda: "Se ela morrer - referindo-se à mãe idosa —, o que será de mim?". Essas frases podem ser traduzidas: "O que será do meu eu diante do fato da morte?"; "Como posso viver tendo diante de mim o fato inexorável da morte, da minha finitude, do meu desamparo?".

Recusar a ideia da morte é uma forma de proteção, legítima, é claro, que nos leva a dar ênfase à causação fortuita, contingente da existência da finitude tal como as doenças, a idade avançada etc. No entanto, quando ocorre um grande número de mortes somos então atingidos de forma direta, profunda e radical, pois o que se revela é a face do sem sentido da vida, do inominável que o cotidiano tende a encobrir.

Conforme indica Freud (1915a/1977a), não existe a ideia de morte no inconsciente, visto que, diferentemente da consciência, seu funcionamento segue 


\section{EDITORIAL}

a atemporalidade. O inconsciente é, de fato, o infantil. A estrutura e o modo de funcionamento do inconsciente revelam que o sujeito desejante não envelhece jamais e não crê, portanto, na sua morte. Esse fato expressa a cisão do sujeito em relação à consciência, aos valores morais adquiridos ao longo da vida que, muitas vezes, trazem como efeito a ilusão da autonomia e da vontade própria.

É o encontro com o real oriundo das catástrofes que nos obriga a encarar a morte, não sendo possível desmenti-la. Constatamos que: "As pessoas realmente morrem e não apenas uma a uma, porém, às dezenas e, às vezes, milhares num único dia" (1915b/1977b, p. 329). A morte deixa de ser pura contingência. Como recobrir essa verdade quando ela se apresenta diante de nossos olhos?

O encontro com o inominável da morte cria uma fissura interna que, por outro lado, pode produzir mudanças radicais na vida de uma pessoa. Uma moça em análise dizia: "Quando descobri o câncer, o chão se abriu sob meus pés, mas depois o que apareceu foi a urgência, a urgência de vida, como nunca tinha sentido antes".

Freud chama a atenção para a inclinação que temos de não computar a morte no cálculo da vida, tendência que gera muitas outras renúncias e exclusões impedindo-nos de viver a vida plenamente. É de fato o reconhecimento da presença da morte na vida aquilo que nos permite dar à vida seu pleno sentido e que pode produzir um salto qualitativo na existência.

Essa constatação fica muito bem delineada no belo artigo freudiano, "Sobre a transitoriedade" (1916/1977c), quando descreve um passeio nos Alpes com dois amigos, sendo um deles um jovem poeta famoso (Rainer Maria Rilke).

Freud indica que, apesar de admirar toda a beleza à sua volta, o poeta não extraía daí nenhuma alegria, pois perturbava-o a ideia de que todas as coisas são efêmeras e que, por isso, estão fadadas à transitoriedade. Ou seja, a constatação de que as coisas não têm permanência absoluta destituiria das mesmas o seu valor.

O que sublinha nesse artigo é a presença de duas tendências psíquicas diante da transitoriedade: um penoso desalento, como expressa o poeta, ou, ainda, uma rebelião, uma revolta contra o fato da efemeridade das coisas.

Enquanto o penoso desalento revela a presença de uma atitude melancólica diante da existência, a atitude de revolta, por sua vez, demonstra ser um produto dos nossos desejos inconscientes, tal como indicado anteriormente, e a expectativa de uma exceção em favor do belo e do perfeito. Afirma, porém, que aquilo que é doloroso é, também, o verdadeiro que desvela algo da vida. 
Sublinha, enfaticamente, que reconhecer o doloroso e a transitoriedade não retira o valor do belo e de tudo o que existe. Ao contrário, implica a possibilidade de um aumento no valor das coisas. Indica que: "O valor da transitoriedade é, exatamente, o da escassez do tempo" (Freud, 1916/1977c, p. 345).

Reconhecer a escassez do tempo é reconhecer o real da vida entrelaçada à morte. Ou seja, a transitoriedade e a finitude apontam para um limite, uma restrição do gozo da vida, mas, por outro lado, eleva seu valor e o torna mais apreciavelmente real.

A beleza da natureza destruída, indica Freud (1916/1977c), retorna mais uma vez e em relação às nossas vidas pode ser considerada eterna. "O valor do belo e do perfeito está determinado unicamente por sua significação para nossa vida sensitiva e independe de duração absoluta" (p. 346). O belo, o perfeito, a felicidade nada mais são do que o instante.

O não reconhecimento da transitoriedade e de seu valor tem relação com as dificuldades que temos de realizar o luto. Os objetos que nos possibilitam prazer tornam-se parte de nós mesmos. A guerra, os conflitos sociais e as catástrofes, de modo geral, nos privam dos nossos objetos, de uma parte de nós mesmos e, por isso, tendemos a nos apegar ao que sobrou de tudo isso. O que sobrou nos reporta ao que foi e ao que é. Temos, aqui, o valor fundamental da preservação da memória na vida individual e coletiva.

Tal constatação lembra uma colocação do escritor argentino Jorge Luis Borges (2000) quando considera que a memória é a afirmação da vida para além da morte.

A ideia da vida, vinculada à memória, destaca a importância do simbólico no contorno do traumático. Lacan insiste na importância da lápide que não só assegura a memória póstuma dos entes queridos, mas, também, permite uma marca do fim. Algo fundamental, pois viabiliza que o luto se processe. Nesse sentido, a morte biológica, sua decretação, nunca é suficiente, pois ela só existe, de fato, quando demarcada pelo simbólico.

Tal constatação define a importância de todos os rituais criados em torno da perda de entes queridos, a necessidade que temos de enterrar nossos mortos e todo o dramático sofrimento em torno da dificuldade de realizar a morte dos desaparecidos.

(O resgate dos desaparecidos, de seus restos mortais, assim como o atestado de óbito, revela, aqui, toda sua importância. Como a morte é a presença do inominável, atestá-la é uma forma de nomeá-la viabilizando, em alguma medida, o luto dos familiares.) 
Como afirma Freud, o luto exige um tempo de mobilização das representações simbólicas. O ponto é que a capacidade de fazer o luto é colocada em questão, e temos que nos defrontar com nossa própria finitude antecipando, nesse sentido, a morte própria.

Talvez o mais difícil de todos os trabalhos clínicos, e que mais nos coloca à prova, seja o processo de acompanhar alguém com uma doença terminal ou mesmo ouvir um discurso sobre a morte. Isso porque somos obrigados a nos aproximar da finitude e nos encontrar com o não senso radical da vida. mesmo?

Tal ponto nos leva à questão paradoxal: é possível fazer o luto de si

A palavra, talvez, não seja exatamente luto, mas parece ter sido essa ideia que levou o psicanalista inglês D. Winnicott, a afirmar, certa vez, que gostaria de estar bem vivo, presente, no momento da sua morte, pois não queria ver-se excluído dela.

De certa forma, fazer o luto de nós mesmos é a proposta da psicanálise. Processo de destituição subjetiva, onde precisamos rever nossos ideais, aproximando-nos de um encontro consentido com o inominável.

Para que isso seja possível é preciso, indiscutivelmente, a presença do outro. Testemunha, interlocutor, que possa ouvir e reconhecer com total desapego a palavra que advém do sujeito em sofrimento. Essa é a função do psicanalista. Mas é, também, uma experiência que pode ser compartilhada por todo ser falante que se deixe afetar pela radicalidade da existência humana.

Para aqueles que nem sequer puderam dizer a última palavra, porque encontraram a morte repentina, resta a possibilidade de reconhecimento na memória daqueles que ficaram. Resta, ainda, o apoio a ser dado às famílias que sofreram com essa tragédia.

A ideia de solidariedade no direito romano expressava, primitivamente, as responsabilidades individuais em relação à comunidade. Tal ideia aponta para a importância da memória social como fator que traz para cada indivíduo de uma comunidade o sentimento de pertencimento tão fundamental ao convívio humano.

Seguindo Freud, podemos apostar que as marcas, os restos deixados pelo que foi destroçado são também as marcas de um possível recomeço que tenha como referência o sentimento comum da solidariedade.

Como afirma Saramago (1996): "Somos a memória que temos e a responsabilidade que assumimos" (p. 63). A responsabilidade social se traduz 
e se move no campo individual pela presença do desejo que nos habita e que depende, desde as suas origens, da presença do outro.

\section{Referências}

Borges, J. L. (2000). Esse oficio do verso. São Paulo, SP: Editora Schwarcz.

Freud, S. (1977a). O inconsciente. In Edição Standard Brasileira das Obras Psicológicas Completas de Sigmund Freud (v. XIV, pp. 185-245). Rio de Janeiro, RJ: Imago. (Trabalho originalmente publicado em 1915a).

Freud, S. (1977b). Reflexões sobre os tempos de guerra e de morte. In Edição Standard Brasileira das Obras Psicológicas Completas de Sigmund Freud (v. XIV, pp. 311-341). Rio de Janeiro, RJ: Imago. (Trabalho originalmente publicado em 1915b).

Freud, S. (1977c). Sobre a transitoriedade. In Edição Standard Brasileira das Obras Psicológicas Completas de Sigmund Freud (v. XIV, pp. 344-348). Rio de Janeiro, RJ: Imago. (Trabalho originalmente publicado em 1916).

Freud, S. (1977d). O mal-estar na civilização. In Edição Standard Brasileira das Obras Psicológicas Completas de Sigmund Freud (v. XXI, pp. 75-171). Rio de Janeiro, RJ: Imago. (Trabalho originalmente publicado em 1930).

Lacan, J. (1974-75). O seminário. Livro 22. RSI. Lição 8 de abril de 1975. Pas-Tout Lacan. Seminaires Jacques Lacan. Recuperado em 4 jan. 2019 de: $<$ http://ecolelacanienne.net/wp-content/uploads/2016/04/seminaire_seminario_transcription ALI_1974_1978.pdf>.

Saramago, J. (1996). Cadernos de Lanzarote II. Lisboa, Portugal: Editorial Caminho.

Citação/Citation: Leite, S. (2019, março). Editorial. O inominável e a transitoriedade. Revista Latinoamericana de Psicopatologia Fundamental, 22(1), 11-19. http://dx.doi.org/10.1590/1415-4714.2018v22n1p11.1.

Editores do artigo/Editors: Ana Maria Galdini R. Oda

Recebido/Received: 31.1.2019 / 1.31.2019 Aceito/Accepted: 10.2.2019 / 2.10.2019 


\section{EDITORIAL}

Copyright: (C) 2009 Associação Universitária de Pesquisa em Psicopatologia Fundamental/ University Association for Research in Fundamental Psychopathology. Este é um artigo de livre acesso, que permite uso irrestrito, distribuição e reprodução em qualquer meio, desde que o autor e a fonte sejam citados / This is an open-access article, which permits unrestricted use, distribution, and reproduction in any medium, provided the original authors and sources are credited.

\section{Sonia LeITe}

Psicóloga; Psicanalista; Coordenadora Adjunta da Residência Multiprofissional em Saúde Mental (RMSM) SES/UERJ (Rio de Janeiro, RJ, Br); Professora e supervisora da RMSM; Doutora em Psicologia Clínica pela Pontifícia Universidade Católica do Rio de Janeiro PUC/RJ (Rio de Janeiro, RJ, Br); Editora da Revista Latinoamericana em Psicopatologia Fundamental; Membro do Corpo Freudiano Escola de Psicanálise Seção RJ; Coordenadora de Ensino do Corpo Freudiano Escola de Psicanálise - Seção Rio de Janeiro.

Rua Conde de Bonfim, 232/712

20520-051 Rio de Janeiro, RJ, Br.

https://orcid.org/0000-0002-3898-088X

soniacleite@uol.com.br

This is an open-access article, which permits unrestricted use, distribution, and reproduction in any medium for non-commercial purposes provided the original authors and sources are credited. 